\title{
MIMIKRI PRIBUMI TERHADAP \\ KOLONIALISME BELANDA \\ DALAM NOVEL SITTI NURBAYA KARYA MARAH RUSLI \\ (Kajian Postkolonialisme)
}

\author{
oleh Hartono \\ FBS Universitas Negeri Yogyakarta
}

\begin{abstract}
This study was conducted by using postcolonialism theory. This study of postcolonialism, focused on mimikri or indigene's imitation to Dutch colonials in Sitti Nurbaya novel by Marah Rusli, intended to uncover and describe some aspect of Dutch colonialism culture which they were imitated by indigene society. This study also attempt to describe fiction element that was used by writer to convey imitation of Dutch colonialism culture.

This study showed that ini the novel of Sitti Nurbaya by Marah Rusli was found mimikri to Dutch colonialism which was executed by the characters. They are Sitti Nurbaya, Samsul Bahri, Datuk Maringgih, Arifm, and Bachtiar. Well, the Dutch colonialism culture that was imitated by them are (1) language, (2) feast and equipment of human life (clothes and weapon), (3) work system (trade), (4) artistry (art of music and art of movement), and (5) science. Fiction element that was used by writer to uncover that mimikri realization is characterization element.
\end{abstract}

Keywords: mimikri, postcolonialism

\section{A. Pendahuluan}

Bangsa Indonesia mengalami masa penjajahan cukup lama. Masa penjajahan Kolonial Belanda saja sudah mencapai kurang lebih tiga ratus lima puluh tahun, belum lagi penjajah yang lain. Karena lamanya bangsa Indonesia berada dalam kekuasaan bangsa lain itulah, budaya kolonial Belanda sebagai penjajah cukup banyak berpengaruh dalam kehidupan bangsa Indonesia.

Pada masa penjajahan, khususnya penjajahan Belanda itu, hubungan penjajah dengan masyarakat terjajah berlangsung secara 
vertikal. Masyarakat jajahan ditempatkan oleh penguasa Belanda sebagai masyarakat yang dikuasai. Sebaliknya, pemerintah Belanda berada pada strata sosial penguasa yang menciptakan hubungan itu menjadi hubungan bersifat patront-client. Dalam pandangan Barat, masyarakat Timur sebagai sosok the Orient, sebaliknya Barat merupakan sosok the Occident. Barat selalu superior sedangkan Timur sebagai inferior (Said, 1996:3). Penjajah menempatkan diri sebagai subjek, arogan, dan superior di hadapan masyarakat pribumi (Faruk, 1998:2). Gambaran dan sifat serta tabiat manusia Indonesia dalam sastra Hindia Belanda adalah orang yang malas, bodoh, jorok, dan serba lamban. Bangsa Indonesia juga dinilai sebagai bangsa yang lamban, suka ngomong, dan boros dengan uang (Sastrowardoyo, 1983:18).

Dalam perkembangan kekuasaan kolonial Belanda telah terjadi perubahan cara pandang penguasa kolonialis dalam penetapan status sosial pada masyarakat jajahannya. Menurut Sastrowardoyo (1983:23) sejak abad ke-17 dan ke-18 telah tumbuh sistem status sosial masyarakat jajahan yang didasarkan pada ras. Pada tahun 1850, pemerintah Belanda menetapkan sistem stratifikasi sosial penduduk Hindia Belanda dalam kaitannya dengan politik, ekonomi, dan sosial yang bersifat berjenjang, yaitu (1) bangsa Belanda dan Indo, (2) bangsa Timur asing, misal Arab dan Cina, dan (3) masyarakat pribumi. Eksistensi status tersebut salah satunya tampak dalam karya sastra Hindia Belanda yang bercerita tentang masyarakat jajahan.

Dalam stratifikiasi kolonialisme, masyarakat pribumi memiliki posisi lebih rendah dibandingkan dengan orang-orang Belanda (Eropa) maupun bangsa Timur asing seperti Arab dan Cina. Dalam kaitan ini tentu terjadi idealisasi pada kelompok berstatus sosial bawah (pribumi) terhadap golongan yang berstatus sosial yang lebih tinggi. Orang-orang pribumi ingin memiliki status sosial yang lebih tinggi, sehingga sering terjadi peniruan-peniruan terhadap budaya yang dimiliki oleh penjajah, yaitu kolonial Belanda yang oleh sebagian masyarakat pribumi dianggap memiliki budaya yang lebih tinggi.

DIKSI Vol.12, No.2, Juli 2005 
Menurut Ricklefs (1995:228), munculnya kebijakan Politik Etis pada tahun 1901 tidak terlepas dari pandangan Belanda yang semula menempatkan masyarakat pribumi sebagai objek yang dapat diatur sesuai kepentingannya. Masyarakat pribumi harus dibimbing memasuki dunia modern dan diperkenalkan pada peradaban Barat yang lebih maju agar tercapai kesesuaian antara Barat dan Timur (Setiadi, 1991:25). Menurut Rosidi (1965:3), adanya politik etis tersebut menunjukkan bahwa pemerintah kolonial Belanda sudah berlaku lebih lunak terhadap pribumi sebagai balas jasa dan tanggung jawab moral. Walaupun hal tersebut tidak terlepas dari kepentingan penjajah dalam menjaga dan melanggengkan dominasinya terhadap pribumi (Setiadi, via Pardi, 1999:20).

Dengan adanya politik etis, pemerintah Belanda memberi peluang kepada pribumi untuk memasuki sekolah-sekolah Eropa yang sekaligus merupakan kesempatan bagi pribumi untuk mendapat kemajuan (Rosidi, 1965:3). Hal ini juga merupakan kesempatan pribumi untuk meningkatkatkan martabat dirinya agar setara dengan martabat bangsa penjajah. Upaya peningkatan martabat diri pribumi tersebut ditempuh dengan berbagai cara. Salah satu di antaranya adalah dengan cara meniru budayanya atau mimicry.

Berbagai hal yang ada hubungannya dengan perilaku bangsa terjajah dalam usahanya menyamakan strata sosialnya dengan bangsa penjajah merupakan salah satu hal yang ada dan diadakan oleh masyarakat pribumi. Hal ini tidak hanya ada dalam masyarakat saja, namun sampai pada karya sastra pun banyak yang mengungkapkan budaya Untuk itu, budaya mimikri atau peniruan tersebut periu dikaji dan diteliti terutama yang ada dalam karya sastra.

Karya-karya yang ditulis oleh para pengarang, menurut Said (1994:23-24), selain merupakan hasil imajinasi kreatif atau interpretative yang kaya, juga merupakan bagian dari hubungan antara kebudayaan dan imperium. Menurutnya, para pengarang itu sangat terlibat dalam sejarah mereka, membentuk dan dibentuk oleh sejarah serta pengalaman sosial mereka dengan kadar yang berbeda-beda. Kebudayaan dan bentuk-bentuk estetika yang dikandungnya, termasuk di dalamnya karya sastra, berasal 
dari pengalaman sejarah.

Di samping karena adanya fenomena kehidupan, kelahiran karya sastra juga karena adanya kesadaran penulisnya bahwa karya sastra sebagai sesuatu yang imajinatif, dan inventif harus mengemban misi-misi yang dapat dipertanggungjawabkan serta bertendens (Suyitno, 1990:3). Pengarang mencipta karya tidak hanya didorong oleh hasrat untuk menciptakan keindahan, tetapi juga berkehendak untuk menyampaikan pikiran, perasaan, pendapat, dan kesan-kesannya terhadap sesuatu. Karya sastra yang baik tentu mengandung nilai-nilai kehidupan seperti nilai religi, falsafi, dan nilai kehidupan lainnya. Dengan demikian karya sastra dapat dilihat sebagai bentuk filsafat atau pemikiran yang terbungkus dalam bentuk khusus (Wellek, 1990:134). Oleh karena itu, karya sastra dapat dikaji untuk mengungkapkan pikiranpikiran yang terkandung di dalamnya, baik yang tersurat maupun tersirat.

Kajian postkolonialisme dengan fokus mimikri pribumi terhadap kolonialisme Belanda dalam novel Sitti Nurbaya karya Marah Rusli ini salah satunya dilatarbelakangi oleh belum adanya atau belum banyaknya kajian sastra yang mengungkap masalah kolonialisme dalam karya sastra dan juga adanya sinyalemen dari Setiadi- (1991:24) dan Said (1994:104) yang menyatakan bahwa sampai dengan saat ini belum ada studi yang mengaitkan keberadaan kolonialisme Barat (Belanda) dengan budaya masyarakat terjajah, belum mendapat perhatian yang memadai.

Dari latar belakang masalah tersebut masalah dalam kajian ini adalah aspek atau unsur-unsur budaya kolonialisme Belanda apa saja yang ditiru oleh pribumi dalam novel Sitti Nurbaya karya Marah Rusli dan unsur fiksi apa sajakah yang digunakan pengarang untuk menyampaikan tiruan budaya kolonialisme Belanda tersebut.

Kajian postkolonialisme dengan fokus mimikri atau peniruan pribumi terhadap kolonialisme Belanda dalam novel Sitti Nurbaya karya Marah Rusli ini bertujuan untuk mengungkapkan dan mendeskripsikan aspek-aspek budaya kolonialisme Belanda yang ditiru oleh masyarakat pribumi dalam novel Sitti Nurbaya karya Marah Rusli. Selain itu, artikel ini juga berusaha untuk mengungkapkan dan mendeskripsikan unsur 
fiksi yang digunakan pengarang untuk menyampaikan peniruan budaya kolonialisme Belanda dalam novel Sitti Nurbaya karya Marah Rusli.

\section{B. Teori Postkolonial}

Menurut Appiah (via Ashcroft, 1995:117) postkolonial bukan berarti Post-independence' (pasca/setelah kemerdekaan) atau 'after colonialism'(setelah zaman penjajahan), karena postkolonial bukan ujung atau akhir dari proses kolonial. Postkolonial menurut Appiah lebih sebagai akibat paling awal dari kontak dengan kolonial. Postkolonial merupakan wacana pertentangan yang disebabkan oleh kolonialisme. Postkolonial juga mencakup semua budaya yang terkena imbas kolonialisme atau imperialisme sejak zaman penjajahan hingga hari ini.

Konsep dasar postkolonial didasarkan pada pemikiran Said (1994) yang menggugat wacana tentang Timur sebagai suatu produksi ilmu pengetahuan yang mempunyai landasan ideologis dan kepentingan kolonial. Didukung oleh tradisi, kekuasaan, lembaga dan berbagai modus penyebaran pengetahuan, wacana tersebut menciptakan mitos dan stereotip tentang Timur yang dikontraskan dengan Barat. Hal itu merupakan cermin negatif untuk membesarkan citra Eropa sebagai pelopor peradapan.

Postkolonial bisa dipahami sebagai efek tekstual atau strategi pembacaan. Secara praktis postkolonial bekerja dalam dua tataran. Pada tataran pertama, postkolonial diartikan sebagai upaya untuk menjelaskan postkolonialisme yang melekat pada teks-teks tertentu. Pada tataran kedua, postkolonial diartikan sebagai upaya untuk menyingkap dan membongkar (dekonstruksi) kekuasaan kolonialisme yang teraktualisasi dalam wacana sastra postkolonial. Wacana sastra postkolonial adalah wacana sastra yang melihat secara kritis hubungan kekuasaan yang terjadi dalam sistem kolonialisme yang terlihat dalam teks-teks sastra (Boehmer dalam Dewi, 2000:1). Secara umum sastra postkolonial menunjuk pada semua praktik penulisan dan pembacaan tentang pengalaman-pengalaman kolonial yang terjadi di luar Eropa sebagai akibat ekspansi dan eksploitasi yang dilakukan oleh bangsa Eropa terhadap bangsa-bangsa lain. Sastra 
postkolonial mempertanyakan sekaligus menentang ide-ide universal yang ditanamkan dalam sastra Barat. Sastra postkolonial berfungsi dan menempatkan diri sebagai counter-discourse terhadap wacana yang berbau imperalis (Dewi dalam Noor, 2002:33).

Yang dimaksud dengan teori postkolonial adalah teori yang dipergunakan untuk menganalisis berbagai gejala kultural, seperti: sejarah, politik, ekonomi, sastra, dan sebagainya, yang terjadi di negaranegara bekas koloni Eropa modern. Pada umumnya gejala-gejala kultural tersebut terkandung dalam berbagai teks studi mengenai dunia timur, yang ditulis oleh para orientalis, yang disebut sebagai teks-teks oriental. Meskipun demikian, sebagai akibat dominasi intelektualitas Barat, banyak juga karya yang melukiskan ketidakseimbangan hubungan antara masyarakat Barat dan masyarakat Timur yang ditulis oleh intelektualitas pribumi yang telah terkonstruksi oleh pemikiran Barat (Ratna, 2004:206).

Menurut Bill Ashcroft dkk. (via Ratna, 2004:207) teori postkolonial mencakup seluruh khasanah sastra nasional yang pernah mengalami kekuasaan imperial sejak awal kolonisasi hingga sekarang. Sastra yang dimaksudkan, di antaranya: Afrika, Australia, Bangladesh, Canada, Karibia, India, Malta, Selandia Baru., Pakistan, Singapura, Kepulauan Pasifik Selatan, Sri Lanka, Malaysia, dan Indonesia.

Dalam kaitannya dengan studi sastra, postkolonial bekerja pada wilayah yang luas. Lo dan Gilbert (1998:5-13) menyebutkan beberapa problem yang menyangkut budaya kolonial sebagai persoalan dalam studi sastra postkolonial. Problem tersebut adalah masalah bahasa, sejarah, nasionalisme, kanonitas, tempat, politik tubuh, dan hibriditas atau pencampuran budaya penjajah terjajah. Sementara itu, berbagai kemungkinan keagenan yang tercakup dalam studi ini adalah hibriditas, mimikri, dan ambivalensi.

Menurut Lo \& Gilbert (1998:2), dan Ashcroft, dkk. (1995:1-2) studi postkolonialisme memunculkan idealisasi berupa resistensi. Munculnya sikap resistensi dalam wacana postkolonial ini merupakan konsekuensi logis dari berbagai representasi tidak adil yang dilakukan

DIKSI Vol.12, No.2, Juli 2005 
kaum kolonial terhadap jajahannya. Berbagai representasi tersebut dilestarikan melalui berbagai media pendidikan dan hiburan, seperti pertunjukkan televisi, kartun, dan novel (Lahpan via Noor, 2002:35).

Konsep mimikri dalam penelitian ini diartikan sebagai tindakantindakan individual yang memerlukan kadar keterlibatan. Tindakan mimikri ini merupakan bentuk resistensi dari dalam, potensi subversib yang ditempatkan dalam wilayah antara peniruan dan pengejekan yang datang dari proses kolonial ganda (Noor, 2002:37). Sementara itu, resistensi radikal dilakukan masyarakat terjajah terhadap otoritas kolonialisme yang dirasakan.

Menurut Kluckhohn (via Soekiman, 2000:41-42) Budaya Eropa atau Belanda yang biasanya ditiru oleh golongan pribumi meliputi tujuh unsur budaya universal (cultural universal), yaitu (1) bahasa (lisan dan tertulis), (2) peralatan perlengkapan hidup manusia (pakaian, rumah, senjata, alat transportasi, alat produksi, dan lain-lain), (3) sistem mata pencaharian hidup (pertanian, pertenakan, sistem produksi, dan sebagainya), (4) sistem kemasyarakatan (organisasi politik, sistem hukum, sistem perkawinan, dan sebagainya), (5) kesenian (seni rupa, seni sastra, seni suara, seni gerak, dan sebagainya), (6) ilmu pengetahuan, dan (7) sistem religi

\section{Bentuk Mimikri Pribumi terhadap Kolonialisme Belanda}

Problem pertama masyarakat terjajah dalam menghadapi wacana penjajah adalah problem emansipasi melalui cara peniruan atau mimikri yang ambivalen karena di satu pihak membangun identitas atau persamaan, tetapi di lain pihak mempertahankan perbedaan (Faruk, 2001:72).

Sebagaimana diungkapkan oleh Kluckhohn (via Soekiman, 2000: 41-42) bahwa budaya Eropa atau Belanda yang biasanya ditiru oleh golongan pribumi itu ada tujuh unsur budaya universal (cultural universal). Namur, Bari kajian yang dilakukan terhadap novel Sitti Nurbaya karya Marah Rush, dari ketujuh unsur tersebut yang ada dan ditiru oleh masyarakat pribumi hanya lima unsur budaya universal. Kelima unsur budaya universal tersebut adalah (1) bahasa, (2) peralatan 
perlengkapan hidup manusia (pakaian dan senjata), (3) sistem mata pencaharian hidup (perdagangan), (4) kesenian (seni suara dan seni gerak), dan (5) ilmu pengetahuan.

\section{Mimikri Penggunaan Bahasa}

Mimikri atau peniruan kolonialisme Belanda yang banyak dilakukan oleh tokoh cerita dalam novel Sitti Nurbaya karya Marah Rusli adalah peniruan terhadap bahasa Belanda. Bahasa adalah kunci untuk membuka ilmu pengetahuan dan ilmu pengetahuan adalah jalan menuju peradapan. Mereka menggunakan bahasa Belanda untuk kegiatan tertentu saja. Hal ini dilakukan oleh Sitti Nurbaya, Samsulbahri, Datuk Maringgih, Arifm, dan Bahtiar. Sitti Nurbaya, Samsulbahri, Arifin, dan Bakhtiar meniru bahasa Belanda melalui pendidikan formal di sekolah. Bahasa Belanda digunakan dalam komunikasi formal. Dalam komunikasi sehari-hari mereka tidak menggunakan bahasa Belanda.

Contoh penggunaan bahasa Belanda ini dapat dilihat pada kutipan berikut ini.

Tatkala sampai ia ke dekat Nurbaya dan terlihat olehnya kecantikan perempuan ini, berbisik-bisiklah ia dengan beraninya, dalam bahasa Belanda, "Bagaimana pikiranmu tentang perempuan ini, Ludi?"

"Ini sesungguhnya bunga ros dari Padang,"jawab Ludi.

"Sanggup engkau membujuknya? Selusin bir upahnya," kata mualim itu pula.

Segala percakapan ini di dengar dan dimaklumi oleh Nurbaya dan sangatlah benci hatinya melihat kedua mereka. Tetapi ditahannya marahnya, supaya ia jangan dianiaya pula oleh mereka.

(Rusli, 2002:175)

DIKSI Vol.12, No.2, Juli 2005 
Nurbaya lalu berdiri dan menolakkan Ludi, sambil berkata dalam bahasa Belanda, "Jika berani engkau mengganggu aku sekali lagi, kuadukanlah kelakuanmu yang tiada senonoh ini kepada kapiten kapal. Akan menyusahkan penumpanglah kerjamu di sini?"

(Rusli, 2002:78)

Sebagaimana yang dikemukakan oleh Faruk (2001:76) bahwa peniruan penggunaan bahasa Belanda tidak secepat dan sebanyak peniruan dalam gaya hidup. Hal ini terjadi karena tekanan politik bahasa dari penguasa kolonial Belanda itu sendiri. Menurutnya, peniruan yang segera tersebar itu memang bukan dalam penggunaan bahasa Belanda. Yang lebih mudah dan lebih cepat dilakukan oleh masyarakat setempat terutama sekali adalah peniruan gaya hidup orang Eropa (Belanda).

\section{Mimikri terhadap Peralatan Perlengkapan Hidup Manusia}

Dalam novel Sitti Nurbaya karya Marah Rusli, peniruan terhadap unsur budaya Peralatan Perlengkapan Hidup Manusia dilakukan oleh Sitti Nurbaya, Samsulbahri, Arifin, dan Bakhtiar dalam bentuk pakaian. Selain pakaian, Samsulbahri juga menggunakan pistol atau senjata sebagai perlengkapan hidup. Ketika sekolah dokter di Jakarta, Samsulbahri membawa pistol.

Contoh mimikri terhadap Peralatan Perlengkapan Hidup Manusia dapat dilihat dalam kutipan berikut ini.

Pakaiannya baju jas tutup putih dan celananya pendek hitam, yang berkancing diujungnya. Sepatunya sepatu hitam tinggi yang disambung ke atas dengan kaus sutera hitam pula dan diikatkan dengan ikatan kaus getah pada betisnya. Topinya topi rumput putih, yang biasa dipakai bangsa Belanda. Di tangan kirinya ada beberapa kitab dengan sebuah peta bumi dan dengan tangan kanannya dipegangnya sebuah belebas, yang dipukul- 
pukulkannya ke betisnya.

Jika dipandang dari jauh, tentulah akan disangka, anak muda ini seorang anak Belanda, yang hendak pulang dari sekolah.

(Rusli, 2002:9)

Pakaian gadis ini pun sebagai pakaian anak Belanda juga. Rambutnya yang hitam dan tebal itu, dijalinnya dan diikatnya dengan benang sutera, dan diberinya pula berpita hitam diujungnya. Gaunnya (baju nona-nona) terbuat dari kain batis yang berkembang merah jambu. Sepatunya dan kausnya, coklat wamanya.

(Rusli, 2002:9)

Dalam hal berpakaian, peniruan yang dilakukan mereka tidak secara keseluruhan tai dipadukan dengan pakaian yang sudah terbiasa mereka gunakan sesuai tradisi. Jadi, peniruan budaya yang dilakukan tidak secara penuh, tetapi hanya sebagian saja. Sarung Bugis dan kopiah hitam tidak ada dalam pakaian orang-orang Belanda, pakaian itu adalah khas pakaian Indonesia. Hal ini dapat dilihat pada kutipan berikut

Memang gagah rupanya Penghulu ini duduk di atas bendinya, bertopangkan tongkat ruyung dengan kedua belah tangannya. Destamya yang berbentuk "ciling menurun" itu adalah sebagai suatu mahkota di atas kepalanya. Bajunya jas putih, berkancingkan "letter W," dan ujung lengan bajunya itu berpetam sebagai baju opsir. Celananya celana panjang putih, sedang di antara baju dan celana kelihatan sarungnya, kain sutera Bugis hitam, yang terjuntai hampir sampai ke lututnya. Sepatunya sepatu kasut yang diperbuat dari kulit perlak hitam.

(Rusli, 2002:18)

DIKSI Vol.12, No.2, Juli 2005 
Walaupun pakaian mereka cara Eropa, tetapi kopiahnya yang hitam itu menyatakan, bahwa mereka bangsa Bumiputra, anak negeri di sana.

Seorang daripada mereka berpangkat dokter dan seorang lagi berpangkat opseter.

(Rusli, 2002:271)

"Setelah kututup lampu itu dengan kertas, supaya terangnya jangan kelihatan dari luar dan kutaruh pistolku di bawah bantalku, berbaringlah pula aku."

(Rusli., 2002:216)

Kalau dilihat latar ceritanya, terutama latar waktu, pada saat itu orang tidak mudah untuk memiliki senjata api, terutama para pelajarnya. Senjata yang mudah dijumpai dan dimiliki oleh mereka adalah senjata tradisional, bukan pistol seperti yang dibawa oleh Samsulbahri. Senjata pistol adalah perlengkapan hidup orang orang Belanda, bukan perlengkapan hidup asli orang Indonesia atau pribumi. Jadi, Samsulbahri meniru budaya kolonial Belanda dalam hal budaya perlengkapan hidup.

Karena tekanan politik bahasa dari penguasa kolonial Belanda, peniruan yang segera tersebar itu memang bukan dalam penggunaan bahasa Belanda. Yang lebih mudah dan lebih cepat dilakukan oleh masyarakat setempat terutama sekali adalah peniruan gaya hidup orang Eropa (Belanda) yang menurut Ahmad Adam (via Faruk, 2001: 76) merupakan manifestasi dari hasrat masyarakat terjajah untuk menyesuaikan diri dengan "kehendak zaman", mencapai kemajuan, dan menempatkan diri sama dengan bangsa penjajah.

\section{Mimikri terhadap sistem mata pencaharian hidup}

Sebelum kedatangan bangsa Eropa terutama Belanda di Nusantara penduduk pribumi hanya mengenal dua jenis pekerjaan yaitu pegawai 
(abdi) kerajaan termasuk pejabat tinggi kerajaan dan tani. Setelah masuknya bangsa Eropa terutama Belanda di Hindia Belanda penduduk pribumi mulai mengenal jenis mata pencaharian hidup yang namanya usaha partikelir atau usaha swasta yang diperkenalkan atau dilakukan oleh usahawan atau investor dari Eropa terutama Belanda.

Dengan demikian, sebagaimana disebutkan Burger (dalam Soekiman, 2000:23) bahwa sampai pada awal abad XX di Hindia Belanda ada beberapa jenis pekerjaan yaitu (a) pamongpraja, (b) pengusaha partikelir, (c) petani, dan (d) buruh. Pekerjaan pamongpraja (pegawai pemerintah) Hindia Belanda sebagian besar diisi oleh golongan Eropa Indo Eropa, dan sebagian kecil diisi oleh golongan pribumi. Pekerjaan pengusaha partikelir diisi oleh pekerja dari tiga golongan yaitu Eropa Indo Eropa, Timur asing terutama Cina, dan pribumi, sedang pekerjaan tani dan buruh sebagian besar diisi oleh pekerja dari golongan pribumi.

Demikian pula dengan mata pencaharian hidup (pekerjaan) yang ada dalam novel Sitti Nurbaya. Pada novel Sitti Nurbaya, pekerjaan pribumi sebagai pedagang atau pengusaha partikelir atau swasta, sebagai dokter, dan obseter pada zamannya dapat dipandang sebagai bentuk peniruan (mimikri) dari sistem mata pencaharian hidup Eropa (Belanda)

Dalam novel Sitti Nurbaya, Datuk Maringgih diceritakan sebagai seorang pedagang yang kaya raya dan termasyhur merupakan salah satu bentuk peniruan terhadap mata pencaharian hidup. Ayah Sitti Nurbaya, Baginda Sulaiman, juga sebagai seorang saudagar yang kaya raya. Samsulbahri masuk sekolah dokter, ingin menjadi dokter tetapi tidak selesai sekolahnya dan akhimya memilih menjadi tentara Belanda, sedangkan kedua temannya, Arifin dan Bakhtiar menjadi dokter dan obseter juga merupakan bentuk peniruan terhadap sistem mata pencaharian hidup. Hal ini dapat dilihat pada kutipan berikut

Temannya yang dipanggil Nur tadi ialah Sitti Nurbaya, anak Baginda Sulaiman, seorang saudagar kaya di Padang, yang mempunyai beberapa toko yang besar-besar, kebun yang

DIKSI Vol.12, No.2, Juli 2005 
lebar-lebar serta beberapa perahu di laut, untuk membawa perdagangannya melalui lautan.

(Rusli, 2002:14)

Itulah Datuk Maringgih,' saudagar pedagang yang termasyhur kayanya, sampai ke negeri-negeri lain. Pada masa itu, di antara saudagar-saudagar bangsa Melayu di Padang, tiada seorangpun dapat melawan kekayaan Datuk Maringgih

(Rusli, 2002:15)

Walaupun pakaian mereka cara Eropa, tetapi kopiahnya yang hitam itu menyatakan, bahwa mereka bangsa Bumiputra, anak negeri di sana.

Seorang daripada mereka berpangkat dokter dan seorang lagi berpangkat opseter. Mereka itu adalah Arifin dan Bahtiar.

(Rusli, 2002:271)

\section{Mimikri terhadap Kesenian}

Anak-anak muda seperti Sitti Nurbaya, Samsulbahri, Arifin, dan Bakhtiar banyak meniru kesenian yang berasal dari Eropa (Belanda) baik musik maupun tarinya. Mereka sudah mengenal dansa dalam pesta. Selain itu, ada pula seni atau budaya minum minuman wiski soda yang dalam budaya tradisi Padang tidak dijumpai sebelumnya. Berikut ini contoh kutipan yang menunjukkan hal itu.

Sejurus kemudian musik pun bermain pula, melagukan lagu wals. Sekalian muda remaja menarilah masing-masing dengan pasangannya. Samsu menuntun tangan Nurbaya, lalu menari bersama-sama.

(Rusli, 2002:69)

Mimikri Pribumi Terhadap Kolonialisme Belanda (Hartono) 
Setelah hari pukul sembilan, masuklah sekalian anak muda itu ke tengah rumah, lalu masing-masing duduk di atas kursi makan. Sup dan anggur dijalankan.

(Rusli, 2002:70)

"Perhatikanlah dahulu perbantahan kita ini," kata Van Sta," dan katakanlah apa yang hendak kau minum?"

"Wiski soda," jawab Mas.

Van Sta lalu meminta dua gelas wish soda kepada bujang rumah bola.

(Rusli, 2002:230)

Acara pesta dengan hidangan sup dan anggur tidak dijumpai dalam budaya Padang, apalagi sampai minum-minuman keras. Demikian pula seni tari dansa yang berpasangan antara pria dan wanita. Dansa adalah salah satu jenis tarian ala Barat, jadi mereka berdansa menirukan budaya orang-orang Eropa atau Belanda.

\section{Mimikri terhadap Ilmu Pengetahuan}

Mimikri terhadap ilmu pengetahuan ini dilakukan oleh Sitti Nurbaya, Samsulbahri, Arifin, dan Bahtiar. Mereka menuntut ilmu di sekolah formal. Bahkan Samsulbahri dan Arifin melanjutkan sekolahnya di Jakarta di sekolah dokter, walaupun akhirnya Samsulbahri tidak dapat melanjutkan sekolahnya sampai selesai. Bakhtiar juga melanjutkan sekolahnya di Sekolah Opseter juga di Jakarta.

Melalui sekolah dan pergaulan atau interaksi sosial dengan orang-orang Belanda peniruan budaya Eropa (Belanda) oleh pribumi lebih mudah berlangsung, termasuk juga sekolah dokter dan opseter yang dijalani oleh mereka bertiga. Untuk lebih jelasnya, berikut ini kutipannya.

DIKSI Vol.12, No.2, Juli 2005 
Seorang dari sahabat Samsu berdiri dengan memegang gelas anggurnya, lalu berpidato. Mula-mula ia memberi selamat kepada Samsu, Arifin, dan Bakhtiar di atas nama sekalian yang datang, karena ketiga mereka telah tamat pelajarannya dalam sekolah Belanda di Padang dan sekarang akan meneruskan pelajarannya di Sekolah Dokter Jawa dan Sekolah Opseter di Jakarta.

(Rusli, 2002:70)

\section{Unsur Fiksi yang digunakan Pengarang untuk Mengungkapkan Mimikri}

Ada beberapa unsur fiksi yang dapat digunakan oleh pengarang untuk mengungkapkan mimikri. Namun demikian, dalam novel Sitti Nurbaya, unsur fiksi yang paling dominan digunakan oleh pengarang untuk mengungkapkan wujud mimikri hanya unsur penokohan, sedangkan unsur cerita yang lain tidak dimanfaatkan.

Kelima bentuk mimikri pribumi terhadap kolonialisme Belanda yaitu (1) bahasa, (2) peralatan perlengkapan hidup manusia (pakaian dan senjata), (3) sistem mata pencaharian hidup (perdagangan), (4) kesenian (seni suara dan seni gerak), dan (5) ilmu pengetahuan itu disampaikan melalui tokoh-tokoh cerita, yaitu Sitti Nurbaya, Samsulbahri, Arifm, Bakhtiar, dan Datuk Maringgih.

Hal ini dapat dipahami karena yang dapat melakukan mimikri atau peniruan budaya adalah tokoh cerita. Para tokoh cerita dalam novel Sitti Nurbaya melakukan peniruan budaya kolonialisme Belanda melalui berbagai aktivitas dalam kehidupan sehari-hari mereka. Aktivitas mereka ini dapat dilihat pada kutipan bentuk-bentuk mimikri yang telah dibahas pada bagian terdahulu. Misalnya:

Nurbaya lalu berdiri dan menolakkan Ludi, sambil berkata dalam bahasa Belanda, "Jika berani engkau mengganggu aku sekali lagi, kuadukanlah kelakuanmu yang tiada senonoh ini 
kepada kapiten kapal. Akan menyusahkan penumpanglah kerjamu di sini?"

(Rusli, 2002:178)

Itulah Datuk Maringgih, saudagar pedagang yang termasyhur kayanya, sampai ke negeri-negeri lain. Pada masa itu, di antara saudagar-saudagar bangsa Melayu di Padang, tiada seorangpun dapat melawan kekayaan Datuk Maringgih

(Rusli, 2002:15)

Seorang dan sahabat Samsu berdiri dengan memegang gelas anggurnya, lalu berpidato. Mula-mula ia memberi selamat kepada Samsu, Arifin, dan Bakhtiar di atas nama sekalian yang datang, karena ketiga mereka telah tamat pelajarannya dalam sekolah Belanda di Padang dan sekarang akan meneruskan pelajarannya di Sekolah Dokter Jawa dan Sekolah Opseter di Jakarta.

(Rusli, 2002:70)

Walaupun pakaian mereka cara Eropah, tetapi kopiahnya yang hitam itu menyatakan, bahwa mereka bangsa Bumiputra, anak negeri di sana.

Seorang daripada mereka berpangkat dokter dan seorang lagi berpangkat opseter. Mereka itu adalah Arifin dan Bahtiar.

(Rusli, 2002:271)

Pada kutipan pertama, yang melakukan mimikri terhadap budaya kolonialisme Belanda adalah Sitti Nurbaya dengan mimikri terhadap bahasa Belanda, sedangkan pada kutipan kedua yang melakukan 
adalah tokoh Datuk Maringgih sebagai seorang saudagar dan pedagang termasyhur. Sementara itu, pada kutipan ketiga dan keempat, yang melakukan mimikri terhadap budaya kolonialisme Belanda adalah Samsulbahri, Arifin, dan Bakhtiar.

Sebagaimana yang dikemukakan oleh Faruk (2001:97) bahwa tokoh-tokoh utama dalam novel ini mempunyai penampilan atau penampakan yang hampir tidak dapat dibedakan dari anak-anak Belanda, padahal sebenamya sepenuhnya pribumi seperti yang terungkap dalam kutipan berikut.

Jika dipandang dari jauh, tentulah akan disangka, anak muda ini seorang anak Belanda, yang hendak pulang dari sekolah. Tetapi jika dilihat dan dekat, nyatalah ia bukan bangsa Eropah; karena kulitnya kuning sebagai kuning langsat, rambut dan matanya hitam sebagai dawat.... (Rusli, 2002:3).

Yang jauh itu adalah yang publik, wacana kolonial yang ditiru, dikutip, dan sekaligus dimobilisasi. Yang dekat itu adalah yang domestik, tuntutan akan emansipasi diri dari penindasan penguasa kolonial, tuntutan akan kemerdekaan, kemandirian, dan pemisahan total masyarakat dan budaya etnis-tradisional dari masyarakat dan budaya kolonial.

\section{E. Kesimpulan}

Dari pembahasan yang dilakukan dapat disimpulkan bahwa dalam novel Sitti Nurbaya karya Marah Rusli terdapat mimikri terhadap kolonialisme Belanda yang dilakukan oleh para tokohnya, yaitu Sitti Nurbaya, Samsulbahri, Datuk Maringgih, Arifin, dan Bakhtiar. Adapun budaya kolonialisme Belanda yang ditiru mereka adalah (1) Bahasa, (2) peralatan perlengkapan hidup manusia (pakaian dan senjata), (3) sistem mata pencaharian hidup (perdagangan), (4) kesenian (seni suara dan seni gerak), dan (5) ilmu pengetahuan. Unsur pembangun fiksi yang digunakan pengarang untuk mengungkapkan wujud mimikri tersebut adalah unsur penokohan. 


\section{DAFTAR PUSTAKA}

Ashcroft, Bill.Cs. (ed). 1995. The Post-Colonial Studies: Readers. London and New York: Routledge.

Dewi, Novita. 2000. "Postkolonial, Pramoedya, Pembangun Pramesywari."

Makalah Seminar Sosiologi Sastra di Fakultas Sastra Universitas Sanata Dharma Yogyakarta,.

Faruk. 1998. "Mimikri: Persoalan Post-Kolonial dalam Sastra Indonesia”.

Makalah Seminar pada An International Research Workshop.

. 2001. Beyond Imagination, Sastra Mutakhir dan Ideologi.

Yogyakarta: Gama Media.

. 2002. Novel-Novel Indonesia Tradisi Balai Pustaka 1920-1942.

Yogyakarta: Gama Media.

Junus, Umar. 1998. "Nyai Dasima dan (Anti/Pasca) Kolonialisme:

Persoalan (Mono/dia)-log".

Kartodirdjo, Sartono, dick. 1987. Perkembangan Peradapan Priyayi.

Yogyakarta: Gadjah Mada University Press.

Loomba, Ania. 2003. Kolonialisme/Pascakolonialisme (diterjemahkan

oleh Hartono Hadikusumo). Yogyakarta: Bentang Budaya.

Noon Rusdian. 2002. "Mimikri dan Resistensi Radikal Pribumi terhadap

Kolonialisme Belanda dalam Roman Bumi Manusia Karya

Pramoedya Ananta Toer". Tesis S2. Universitas Gadjah Mada.

Pardi. 1999. Peniruan Pribumi terhadap Budaya Barat pada Novel Jawa Terbitan Balai Pustaka. (Thesis) Pascasarjana UGM Yogyakarta.

Parry, Benita. 1994. "Problem in Curren Theories of Colonial Discourse"

dalam The Post-Colonial Studies Reader (Ashcroft Editor). London and New York: Routledge.

Ratna, Nyoman Kutha. 2004. Teori, Metode, dan Teknik Penelitian Sastra.

Yogyakarta: Pustaka Pelajar.

Riccklefs, M.C. 1995. Sejarah Indonesia Modern. (Terjemahan Dharmono

Hardjowidjono). Yogyakarta: Gadjah Mada University Press.

DIKSI Vol.12, No.2, Juli 2005 
Rosidi, Ayip. 1965. Kapankah Kesusastraan Indonesia Lahir? Jakarta: Bharata.

Rusli, Marah. 2001. Siti Nurbaya, Cetakan ke-35 . Jakarta: Balai Pustaka.

Said. Edwar W. 1994. Orientalisme. Diterjemahkan oleh Asep Hikmat. Bandung: Pustaka.

. 1996. Kebudayaan dan Kekuasaan: Membongkar Mitos Hegemoni Barat. Diterjemahkan oleh Rahmani Astuti. Cetakan I. Bandung: Mizan.

Sastrowardoyo, Subagio. 1983. Sastra Hindia Belanda dan Kita. Jakarta: PN Balai Pustaka.

Soekiman, Djoko. 2000. Kebudayaan Indies dan Gaya Hidup Masyarakat Pendukungnya di Jawa (Abad XVII Medio Abad X. Yogyakarta: Yayasan Benteng Budaya.

Suryadi. 1998. "Dimensi Negara-bangsa". Paper An International Research Literature. Sydney: The Rex Cramphorn Studio Centre for Performance Studies.

Suyitno. 1996. Sastra Tata Nilai dan Eksegesis. Yogyakarta: Penerbit Hanindita.

Wellek, Rene dan Austin Warren. 1990. Teori Kesusastraan. (Terjemahan Melani Budianta). Jakarta: Gramedia. 